\title{
SUSTENTABILIDADE AMBIENTAL: UM ESTUDO DE CASO NA CEASAMINAS
}

\author{
ENVIRONMENTAL SUSTAINABILITY: A CASE STUDY IN CEASAMINAS
}

\author{
Karina Batista de Aquino \\ Universidade Federal de Minas Gerais \\ karinabatista.aquino@gmail.com
}

\author{
Tatiane de Oliveira Marques ${ }^{1}$ \\ Universidade Federal do Paraná \\ tatianemarques@ufpr.br
}

\begin{abstract}
RESUMO
Este estudo tem como objetivo analisar o índice de sustentabilidade ambiental da Central de Abastecimento de Minas Gerais (CeasaMinas) com a aplicação parcial do Sistema Contábil Gerencial Ambiental (SICOGEA). Os dados foram coletados em três setores da CeasaMinas (contabilidade, meio ambiente e comissão permanente de licitação) por meio da aplicação de questionário (lista de verificação) de 125 questões, proposto na primeira fase da terceira etapa do SICOGEA. Após a aplicação parcial do SICOGEA obteve-se o índice geral de sustentabilidade da CeasaMinas $(40,5 \%)$, classificado como Fraco, porém próximo da classificação Regular, que engloba os resultados de 41 a $60 \%$. Desta forma pode-se dizer que a entidade não alcança, mas está próxima de alcançar, desempenho suficiente para atender a legislação. Dentre os grupos analisados, destaca-se índice de sustentabilidade Fraco para os grupos Produção e Contabilidade e Finanças, e Regular para os grupos Recursos Humanos e Marketing. Destaca-se ainda que o grupo Contabilidade e Finanças apresentou o menor índice de sustentabilidade consequência da falta de relatórios e informações relacionados as ações ambientais.
\end{abstract}

Palavras-chave: Sustentabilidade. CeasaMinas. SICOGEA. Contabilidade ambiental.

\begin{abstract}
This study aims to analyze the Environmental Sustainability Index (ESI) by Minas Gerais Supply Center (CeasaMinas) through the partial application of the Environmental Management Accounting System (SICOGEA). The data were collected through questionnaires containing 125 questions as proposed in the first phase of the third stage of SICOGEA. The answers belong to the CeasaMinas's sectors of accounting, environment and permanent bidding committee. Based on the data the ESI of CeasaMinas is 40.5, which is classified as weak, but it is close to the Regular classification, which includes results from 41 to 60 . This shows that CeasaMinas is close to the minimum performance to comply the legislation. Considering the groups analyzed it can be highlighted a weak ESI by groups related to production and, accounting and finance, and a regular ESI by groups related to human resources and marketing. It should also noted that the lowest ESI was found by the accounting and finance group and this result is due a lack of reports and informations on environmental actions.
\end{abstract}

Key-words: Sustainability. CeasaMinas. SICOGEA. Environmental accounting.

${ }^{1}$ Avenida Prefeito Lothario Meissner, Jardim Botânico - Curitiba, PR - CEP 80210-170 


\section{INTRODUÇÃO}

As empesas têm observado que as questões ambientais e o comprometimento com a redução do impacto ambiental causado por suas atividades produtivas devem ser debatidas, principalmente pela pressão da sociedade, e também devem ser divulgadas informações sobre as ações que tem tomado para reduzir os impactos causados por suas atividades ao meio ambiente. Utilizar os recursos naturais de forma consciente é mostrar a responsabilidade ambiental que a organização possui, o que é um desafio, visto que as organizações devem procurar alternativas de produção que diminuam os danos ambientais (SANTOS; FADEL; SOUZA, 2013).

Diante da preocupação com os impactos ambientais causados pelas atividades empresariais, coube à contabilidade assumir o papel de divulgar as ações voltadas para a gestão ambiental. A contabilidade ambiental passou então a auxiliar os gestores das organizações no intuito de gerenciar os recursos naturais e sociais no ambiente em que estão inseridos, já que a interação entre meio ambiente e empresa deve ser planejada com base em medidas que visem o bem-estar natural e social (LEITE; PIFSCHER; NUNES, 2011).

A gestão ambiental é utilizada pelas empresas para o desenvolvimento e implantação de políticas e estratégias ambientais (KRAEMER et al., 2013) que visem minimizar o impacto ambiental gerado por suas atividades, e é também uma forma de aumentar a competitividade aliada à preocupação com o meio ambiente, atendendo ao interesse dos empregadores (lucratividade) em paralelo com o interesse da sociedade, que é a proteção do meio ambiente (FILHO; SICSÚ, 2003). Por meio de relatórios gerados com informações internas e externas, a gestão ambiental dá suporte à tomada de decisões que envolvam questões ambientais (TINOCO; KRAEMER, 2011).

A necessidade de se obter dados quantitativos e qualitativos que sirvam de auxílio para o gerenciamento ambiental fez com que a contabilidade ambiental ganhasse maior respaldo nos últimos anos (LEITE; PFITSCHER; NUNES, 2011), já que esta surgiu para responder à pressão advinda da sociedade em obter informações sobre os processos ambientais (UHLMANN, 2011). Seguindo essa tendência o Sistema Contábil Gerencial Ambiental (SICOGEA) foi desenvolvido com o intuito de analisar o grau de sustentabilidade ambiental das organizações (PFITSCHER et al., 2009).

Assim, com base nos problemas ambientais que podem ser gerados pelas atividades empresariais e a necessidade de apresentar informações à sociedade, apresenta-se o seguinte problema de pesquisa: qual o nível de sustentabilidade ambiental da Central de Abastecimento 
de Minas Gerais S.A. (CeasaMinas)? Dessa forma, o objetivo dessa pesquisa é analisar o índice de sustentabilidade ambiental da Central de Abastecimento de Minas Gerais (CeasaMinas) com a aplicação parcial do Sistema Contábil Gerencial Ambiental (SICOGEA).

A CeasaMinas, localizada na região metropolitana da cidade de Belo Horizonte, em 2015 movimentou 1,9 mil toneladas de produtos hortigranjeiros e outros produtos alimentícios, possuindo um fluxo médio diário de 53 mil pessoas (CEASAMINAS, 2016), entre produtores rurais, funcionários e clientes. Neste contexto é importante que esta instituição possua um nível de sustentabilidade satisfatório, visto que a mesma está presente no dia-a-dia dos cidadãos mineiros e possui uma atividade que está diretamente interligada ao meio ambiente.

Esta pesquisa está dividida em cinco capítulos. No primeiro capítulo apresenta-se a introdução ao estudo e o problema de pesquisa. No segundo capítulo é explicitado o método e as técnicas da coleta dos dados, como também o método de análise dos resultados, apresentando ainda a delimitação da pesquisa e a amostra objeto de estudo. No terceiro capítulo é apresentada a fundamentação teórica. No quarto capítulo são apresentados os dados e a análise dos resultados. Por fim, é apresentada as considerações finais do estudo e as referências bibliográficas utilizadas.

\section{REVISÃO DA LITERATURA}

\subsection{Sustentabilidade e desenvolvimento sustentável}

O discurso de sustentabilidade dos gestores é voltado para seus funcionários, mercado consumidor, concorrentes, parceiros, ONGs e aos órgãos governamentais, tendo como objetivo fazer com que as práticas gerenciais, ambientais, sociais e econômicas sejam vinculadas a uma imagem positiva da empresa (CLARO, P.; CLARO, D.; AMÂNCIO, 2008).

A sustentabilidade, segundo Sachs (1990) apud Siche et al. (2007, p. 140) "é um conceito dinâmico, pois, considera as necessidades crescentes das populações num contexto internacional em constante expansão". Busca o equilíbrio entre a empresa e o ambiente, onde a empresa se desenvolve competitivamente sem impactar o meio ambiente e preservando o meio para as futuras gerações (LEITE, PFITSCHER, NUNES, 2011). Desta forma a sociedade deve exigir que estas organizações, instituições e empresas se desenvolvam ambientalmente, para que as necessidades da população presente possam ser atendidas sem que haja o comprometimento das futuras gerações de satisfazerem suas próprias necessidades (VELLANI; RIBEIRO, 2009). 
Já o desenvolvimento sustentável é "aquele que atende às necessidades do presente sem comprometer a possibilidade de as gerações futuras atenderem as suas próprias necessidades", deixando claro os princípios que norteiam a sustentabilidade e mostrando que este conceito se desenvolve a longo prazo, pois seus interesses estão pautados nas gerações futuras (CLARO, P.; CLARO, D.; AMÂNCIO, 2008).

Assim, uma organização deve ter seus resultados mensurados e suas decisões orientadas em três esferas inseparáveis - a econômica, a social e a ambiental (PEREIRA, 2007; PIMENTO, 2008), fazendo com que o desenvolvimento sustentável no universo empresarial respeite "os direitos, os valores e os interesses relacionados aos impactos gerados por ela, seja na sociedade, no meio ambiente ou no futuro da própria organização" (PEREIRA, 2007, p. 38).

As organizações devem incorporar a variável ambiental de forma que a tomada de decisão esteja baseada em uma postura responsável no que diz respeito às questões ambientais, possibilitando a identificação de resultados econômicos e estratégicos baseados na causa ambiental (LINS; SILVA, 2009), mesmo que tais resultados não sejam visualizados imediatamente, pois para alcançar tais resultados é necessário que haja planejamento e organização para que a instituição possa atingir a excelência ambiental e consequentemente vantagem competitiva (KRAEMER et al., 2013).

As práticas empresariais sustentáveis são observadas em organizações que conseguem satisfazer a necessidade de seus clientes, gerar valor aos acionistas e à sociedade sem comprometer sua continuidade e a sustentabilidade ecológica dos ecossistemas envolvidos com suas atividades (VELLANI; RIBEIRO, 2009).

A sustentabilidade empresarial pode contribuir para que as empresas além de reduzirem o impacto ambiental, possam buscar vantagem competitiva e diferenciação no mercado, uma vez que a sociedade está cada vez mais engajada em adquirir serviços e produtos de organizações que se diferenciam no mercado (BERNARDES; PFITSCHER; FREITAS, 2012).

\subsection{Gestão ambiental}

As empresas utilizam a gestão ambiental para desenvolver e implantar suas políticas e estratégias ambientais (KRAEMER et al., 2013), bem como com o intuito de reduzir ou eliminar os efeitos negativos provocados no ambiente por suas atividades (TINOCO; KRAEMER, 2011). Na gestão ambiental estão presentes a estrutura organizacional, as atividades de planejamento, responsabilidades, práticas, procedimentos, processos e recursos que visam desenvolver, implementar, atingir, analisar de forma crítica e manter a política ambiental da instituição (TINOCO; KRAEMER, 2011). 
A gestão ambiental também auxilia na geração de relatórios com informações internas e externas que visam dar suporte à tomada de decisões que envolvem as questões ambientais, objetivando a redução dos impactos negativos gerados pelas atividades empresariais e o incentivo à preservação dos recursos naturais (BERNARDES; PFITSCHER; FREITAS, 2012). Gerir a empresa com foco também no meio ambiente passou a ser um fator estratégico para a análise da alta administração das organizações, incluindo uma série de atividades que devem ser administradas, tais como: formular estratégias de administração para o meio ambiente, assegurar a conformidade com as leis ambientais, implementar programas de prevenção à poluição, gerir instrumentos de correção de danos ao meio ambiente, adequar produtos às especificações ecológicas, monitorar o programa ambiental da empresa (TINOCO; KRAEMER, 2011).

Assim, com a demanda da sociedade por informações sobre a questão ambiental das empresas, a contabilidade, além do registro de transações econômicas, passou a apresentar os eventos ambientais, assumindo o papel de divulgação das ações de gestão ambiental, tendo em vista prevenir e corrigir danos, bem como salvaguardar os patrimônios empresarial e nacional (TINOCO; ROBLES, 2006, p. 1078).

A contabilidade da Gestão Ambiental (CGA) visa aumentar a eficiência de materiais, diminuir o impacto e o risco ambiental e reduzir os custos da salvaguarda ambiental, podendose afirmar que ela facilita a transição de informação da contabilidade financeira e da contabilidade de custos (TINOCO; KRAEMER, 2011). Desta forma, a utilização da contabilidade da gestão ambiental pode ser vista como facilitadora do uso e compartilhamento de informações contábeis, para a otimização da eficiência do uso dos recursos naturais, a fim de reduzir o impacto e o risco ambiental e os gastos na preservação ambiental. A questão ambiental, pela sua relevância junto à sociedade moderna, tem de ser incorporada aos demonstrativos contábeis, pois seu impacto sobre os resultados empresariais ocorre a curto, médio e longo prazo (TINOCO; ROBLES, 2006, p. 1079).

Pode-se afirmar, portanto, que a gestão ambiental se faz imprescindível dentro das organizações, sendo um importante instrumento gerencial que visa promover o equilíbrio entre empresa e meio ambiente (BERNARDES; PFITSCHER; FREITAS, 2012). Assim a gestão ambiental torna-se uma ferramenta que visa à sustentabilidade econômica e humana (TINOCO; ROBLES, 2006, p. 1079) e para isso, deve utilizar um adequado Sistema de Gestão Ambiental (SGA), pautado na responsabilidade social que tem por base a sustentabilidade socioambiental, aliada à contabilidade (LEITE; PFITSCHER; NUNES, 2011). 


\section{METODOLOGIA}

Esta pesquisa foi realizada na CeasaMinas, localizada na cidade de Contagem, região metropolitana de Belo Horizonte, Estado de Minas Gerais. A escolha desta instituição se justifica pelo fato de a CeasaMinas ser uma instituição que, direta ou indiretamente, está presente na vida dos cidadãos do estado de Minas Gerais e principalmente da população da região metropolitana de Belo Horizonte, despertando desta forma interesse quanto ao seu nível de sustentabilidade ambiental.

Os dados para realização desta pesquisa foram coletados através de um questionário aplicado aos setores de contabilidade, meio ambiente e comissão permanente de licitação da CeasaMinas. Este questionário, denominado Lista de verificação, foi aplicado através de meio eletrônico (e-mail), com o auxílio da pesquisadora para sanar questões que se fizeram necessárias. A lista de verificação foi aplicada entre 26/04/2016 a 11/05/2016.

A lista de verificação é um dos itens da terceira etapa do método SICOGEA que é "uma ferramenta de gestão ambiental, que une, através de alguns controles, a contabilidade ao meio ambiente", que tem como objetivo gerar informações aos gestores que explicitem os impactos das suas ações no meio ambiente, com o auxílio da contabilidade e controladoria ambiental (SILVA; PFITSCHER, 2014, p. 3916). A lista foi elaborada com base na lista utilizada por Nunes (2010) e adaptada às atividades exercidas pela CeasaMinas. Possui 125 questões fechadas, que se referem às atividades exercidas pela instituição, e foram divididas em 4 grupos, também denominados grupos-chave e 7 subgrupos, conforme Quadro 1. Todas as questões propostas no questionário estão enquadradas nas atividades exercidas pela CeasaMinas, desta forma, não houveram questões que não se aplicavam à instituição, consequentemente, todas as questões foram respondidas.

Quadro 1 - Lista de verificação resumida

\begin{tabular}{|l|c|c|c|c|c|c|}
\hline \multicolumn{5}{|c|}{ LISTA DE VERIFICAÇÃO RESUMIDA } \\
\hline \multicolumn{2}{|c|}{ Grupos e Subgrupos da lista de verificação } & \multicolumn{5}{c|}{ De 0 a 5 minha instituição é: } \\
\hline Grupo 01 - Produção & & & & & & \\
\hline Subgrupo 01 - Fornecedores & & & & & & \\
\hline Subgrupo 02 - Processos de produção & & & & & & \\
\hline Subgrupo 03 - Tratamento de resíduos & & & & & & \\
\hline Grupo 02 - Recursos Humanos & & & & & & \\
\hline Subgrupo 01 - Equipe de colaboradores & & & & & & \\
\hline Subgrupo 02 - Gestão da instituição & & & & & & \\
\hline Grupo 03 - Marketing & & & & & & \\
\hline Subgrupo 01 - Responsabilidade socioambiental & & & & & & \\
\hline Grupo 04 - Finanças e Contabilidade & & & & & & \\
\hline Subgrupo 01 - Contabilidade e auditoria ambiental & & & & & & \\
\hline
\end{tabular}


A lista de verificação foi dimensionada de forma a atribuir uma pontuação que varia em uma escala de atribuição de valor de atendimento por parte da instituição que vai de 0 (zero) a 5 (cinco) e é respondida com base na percepção do entrevistado para cada pergunta do questionário (PFITSCHER et al., 2009). Nesta pesquisa, adotou-se a escala de 1 (um) a 5 (cinco) para os "Pontos Possíveis" a serem atribuídos a cada questão, onde 1 representa uma questão pouco relevante para os propósitos da pesquisa e 5 uma questão muito relevante. Os valores atribuídos para cada questão, Pontos Possíveis, não foram divulgados para o entrevistado, para evitar possíveis direcionamentos e respostas tendenciosas, de acordo com as recomendações de Nunes (2010).

Desta forma, o respondente pode atribuir para cada questão uma pontuação de zero $(0 \%$ - não satisfaz) a cinco (100\% - satisfaz totalmente) quanto ao atendimento da instituição àquele item questionado; e o pesquisador atribui Pontos Possíveis a cada questão, que variam de um (pouco relevante) a cinco (muito relevante). Assim, obtém-se o percentual de atendimento à questão (informado pelo respondente) e aplica-se sobre este o total de Pontos Possíveis atribuídos à questão (atribuído pelo pesquisador), como resultado tem-se os pontos alcançados da instituição em cada questão.

Já o cálculo do índice geral de sustentabilidade ambiental é realizado através da divisão entre os Pontos Alcançados e os Pontos Possíveis (UHLMANN, 2011). Com este cálculo obtêm-se tanto o índice de sustentabilidade geral, quanto dos grupos e subgrupos, conforme demonstrado na Equação 1, utilizada para o cálculo do índice geral de sustentabilidade.

Índice geral de sustentabilidade $=\frac{\text { Pontos Alcançados }}{\text { Pontos Possíveis }}$

Após o cálculo do índice de sustentabilidade é possível verificar se a sustentabilidade da empresa é considerada: Péssima, Fraca, Regular, Boa ou Ótima e qual seu estágio de desempenho ambiental, conforme apresentado no Quadro 2, onde cada categoria do índice de sustentabilidade corresponde a um estágio de desempenho ambiental.

Quadro 2 - Índices de sustentabilidade

\begin{tabular}{|c|l|l|}
\hline \multicolumn{1}{|c|}{ Resultado } & Sustentabilidade & \multicolumn{1}{c|}{ Desempenho: controle, incentivo, estratégia } \\
\hline Inferior a 20\% & Péssima - "P" & Pode estar causando grande impacto ao meio ambiente \\
\hline Entre 21 a 40\% & Fraca - "F" & Pode estar causando danos, mas surgem algumas poucas iniciativas \\
\hline Entre 41 a 60\% & Regular - "R" & Atende somente à legislação \\
\hline Entre 61 a 80\% & Boa - "B" & $\begin{array}{l}\text { Além da legislação, surgem alguns projetos e atitudes que buscam } \\
\text { valorizar o meio ambiente }\end{array}$ \\
\hline Superior a 80\% & Ótima - "O" & $\begin{array}{l}\text { Alta valorização ambiental com produção ecológica e prevenção da } \\
\text { poluição }\end{array}$ \\
\hline
\end{tabular}

Fonte: NUNES, 2010, p 165. 
Para auxiliar a gestão da instituição no aumento dos índices de sustentabilidade ambiental, será utilizado o plano resumido de gestão ambiental, que está previsto na primeira ação da fase de investigação e mensuração da terceira etapa do método SICOGEA - Geração 3 (NUNES, 2010).

Para a definição de quais indicadores de sustentabilidade devem ter prioridade na participação do plano de gestão ambiental, foram utilizados os seguintes critérios (NUNES, 2009, p. 131):

i) escolher os subgrupos com menor pontuação;

ii) reportar-se ao questionário e observar as respostas cujo escore atingiu no máximo o escore 03 , ou seja, $60 \%$ do total de pontos possíveis;

iii) priorizar os temas que atribuiu maior importância no questionário, ou seja, nas questões onde o número de pontos possíveis é maior,

iv) usar o bom senso para compor um plano que possa ser: coerente, exequível e principalmente alinhado com a proposta da organização em estudo.

\section{ANÁLISE E DISCUSSÃO DOS RESULTADOS}

Realizou-se o cálculo do índice geral de sustentabilidade da CeasaMinas, conforme apresentado na Equação 1. Os Pontos Alcançados foram divididos pelos Pontos Possíveis e obteve-se o percentual de sustentabilidade global da CeasaMinas.

$$
\text { Índice geral de sustentabilidade }=\frac{130,40}{322}=40,5 \%
$$

O resultado geral de sustentabilidade da CeasaMinas alcançou um índice de 40,50\%. Este índice enquadra-se no nível de sustentabilidade ambiental considerado como Fraco, conforme classificação apresentada no Quadro 3. Porém a instituição está muito próxima do nível Regular, que se inicia a partir de $41 \%$. Este índice indica que o desempenho ambiental da entidade visa atender somente à legislação. O resultado obtido corrobora com o que foi explicitado através de e-mail pelo chefe da seção de contabilidade da CeasaMinas, no qual informou que a política ambiental da CeasaMinas visa somente o cumprimento do ordenamento legal das esferas municipal e estadual.

Na Tabela 1 são apresentados o nível de sustentabilidade geral, bem como dos gruposchave e seus respectivos subgrupos. 
Tabela 1 - Sustentabilidade geral, dos grupos e subgrupos

\begin{tabular}{l|c|c|c|c}
\multicolumn{1}{c|}{ Grupos e Subgrupos } & $\begin{array}{c}\text { Pontos } \\
\text { possíveis }\end{array}$ & $\begin{array}{c}\text { Pontos } \\
\text { alcançados }\end{array}$ & Percentual & $\begin{array}{c}\text { Nível de } \\
\text { sustentabilidade }\end{array}$ \\
\hline Produção & 126 & 45,4 & $36,03 \%$ & Fraco \\
Fornecedores & 52 & 17 & $32,69 \%$ & Fraco \\
Processos de produção & 38 & 10,2 & $26,84 \%$ & Fraco \\
Tratamento de resíduos & 36 & 18,2 & $50,56 \%$ & Regular \\
\hline Recursos humanos & 98 & 59 & $60,20 \%$ & Regular \\
Equipe de colaboradores & 59 & 31,2 & $52,88 \%$ & Regular \\
Gestão da instituição & 39 & 27,8 & $71,28 \%$ & Bom \\
\hline Marketing & 23 & 10,4 & $45,22 \%$ & Regular \\
Responsabilidade socioambiental & 23 & 10,4 & $45,22 \%$ & Regular \\
\hline Finanças e Contabilidade & 75 & 15,6 & $20,80 \%$ & Fraco \\
Contabilidade e Auditoria Ambiental & 75 & 15,6 & $20,80 \%$ & Fraco \\
\hline Total & 322 & 130,40 & $40,50 \%$ & Fraco \\
\hline
\end{tabular}

Fonte: Dados da pesquisa

Através da análise do índice de sustentabilidade dos grupos (Tabela 1) é possível verificar que nenhum grupo se encontra com o nível de sustentabilidade acima do percentual de $80 \%$, demonstrando que a CeasaMinas não possui grupos com desempenho de sustentabilidade classificados como Ótimo. As instituições que possuem este índice de sustentabilidade são consideradas instituições que possuem alta valorização ambiental com produção ecológica e prevenção de poluição.

O grupo Produção apresentou um percentual de sustentabilidade de 36,03\% (Fraco), sendo composto pelos subgrupos Fornecedores, Processos de Produção e Tratamento de Resíduos. O subgrupo Fornecedores (32,69\% - Fraco), aborda questões baseadas no relacionamento da CeasaMinas com seus fornecedores e estes com o meio ambiente. A CeasaMinas através do Instituto CeasaMinas apoia a Associação dos Catadores de Materiais Recicláveis de Contagem (ASMAC), que permite e viabiliza a coleta de materiais recicláveis como o papelão, o plástico e o papel que podem ser recolhidos junto aos lojistas pelos associados da ASMAC (CEASAMINAS, 2012). No entanto a CeasaMinas não promove nenhum tipo de preferência para os produtos que utilizam menos agrotóxicos, questão que possui relevância para os fins desta pesquisa.

O subgrupo Processos de Produção (26,84\% - Fraco), aborda aspectos do processo de produção e a utilização dos recursos neste processo, como, por exemplo, água e luz, e seus possíveis impactos ao meio ambiente. Em seu relatório de gestão de 2014 a CeasaMinas informou que não possui programas para estimular o consumo racional de papel, energia elétrica e água. Já o subgrupo Tratamento de Resíduos (50,56\% - Regular), foi o melhor percentual do grupo de produção. Este subgrupo debate sobre a forma de destinação dos resíduos, que neste caso o foco é o resíduo orgânico. O Instituto Ceasa possui um programa 
denominado Prodal Banco de Alimentos, onde há o acolhimento dos alimentos excedentes que não foram comercializados, mas que ainda podem ser consumidos, doados pelos comerciantes e produtores. Em 2015 foram recebidos $1.683 .860 \mathrm{~kg}$ e distribuídos $1.189 .220 \mathrm{~kg}$, sendo $121.302 \mathrm{~kg}$ a mais se comparado ao ano 2014. Esses alimentos são distribuídos entre instituições sociais, como asilos e creches, esta ação ajuda a evitar perdas e desperdícios. No entanto, é importante ressaltar que os alimentos que não são comercializados e não podem mais ser consumidos possuem como destinação o aterro sanitário da cidade de Contagem.

O grupo Recursos Humanos apresentou o melhor índice de sustentabilidade, 60,2\% (Regular). Os subgrupos que compõem este grupo são: Equipe de Colaboradores e Gestão da Instituição. O subgrupo Equipe de Colaboradores possui questões voltadas para a relação da instituição com seus funcionários (52,88\% - Regular). A CeasaMinas possui programas sociais voltados aos seus colaboradores, como o Ceasa Cidadã e o Telecentro. O projeto Ceasa Cidadã possui parceria com a Prefeitura Municipal de Contagem e visa alfabetizar e ensinar, a nível fundamental, jovens e adultos que trabalham na CeasaMinas, e também o desenvolvimento de oficinas pedagógicas e laboratórios de aprendizagem. Já o Telecentro é um centro de capacitação em informática e possui como ênfase a transformação social através da inclusão social (CEASAMINAS, 2012). Há ainda um núcleo de promoção de saúde do trabalhador que proporciona assistência de saúde a carregadores, produtores e funcionários das lojas, o foco deste núcleo são as doenças relativas ao trabalho. Há também o Centro de Educação Infantil Educar que oferece educação aos filhos, na faixa de 0 a 5 anos, de funcionários (CEASAMINAS, 2012).

Para o subgrupo Gestão da Instituição (71,28\% - Bom) apresentou o melhor índice entre os subgrupos. Suas ações são voltadas para a forma de como a instituição gerencia suas questões ambientais e sociais, o que explica o índice de sustentabilidade alto, pois, conforme já citado anteriormente, a instituição desenvolve projetos sociais voltados para seus colaboradores, instituições sociais e a comunidade a sua volta.

O grupo Marketing possui somente um subgrupo, Responsabilidade Socioambiental (45,22\% - Regular) e está relacionado ao vínculo da CeasaMinas com o ambiente e a sociedade em que ela está inserida. A CeasaMinas possui uma seção de ouvidoria, criada em 2006, que é responsável por receber, examinar e proceder o encaminhamento das reclamações, elogios, sugestões e denúncias referentes a procedimentos e ações, no âmbito da instituição, com objetivo de aprimorar e/ou corrigir os serviços prestados aos cidadãos e usuários dos serviços 
da entidade e também prestar dados e informações aos gestores, além de estabelecer um meio de relacionamento entre os usuários e a instituição (CEASAMINAS, 2016).

Por fim, o grupo de Finanças e Contabilidade obteve um índice de sustentabilidade de 20,80\% (Fraco). Este grupo possui somente um subgrupo, Contabilidade e Auditoria Ambiental, e apresentou o menor índice de sustentabilidade estando muito próximo do nível Péssimo. As questões deste grupo estão relacionadas com a parte de finanças e evidenciação ambiental que são realizadas através da contabilidade e como justificativa para este indicador, pode-se apontar o fato de a CeasaMinas não possuir auditoria ambiental e também não elaborar o balanço ambiental e a demonstração de valor adicionado (DVA). O balanço patrimonial também não apresenta notas explicativas na área ambiental, apresentando somente esclarecimentos a respeito da política ambiental e da responsabilidade social.

Em consequência do baixo índice de sustentabilidade encontrado neste grupo, o mesmo foi selecionado como principal foco do plano resumido de gestão ambiental proposto para esta instituição. Estruturou-se o plano resumido de forma objetiva, demonstrando as ações e os objetivos que devem ser seguidos pela instituição para que a mesma possa, através da realização das ações previstas no plano, aumentar seu índice de sustentabilidade ambiental.

Dentre as principais ações recomendadas nesse trabalho para a CeasaMinas desenvolver, duas se sobressaem: 1) priorizar os produtores, bem como os produtos, que utilizam menor quantidade de agrotóxicos; e 2) realizar o processo de compostagem com o lixo orgânico que atualmente vai para o aterro sanitário da cidade de Contagem. O produto do processo da compostagem pode ser distribuído para os produtores utilizarem em suas plantações, fazendo com que o alimento produzido dependa menos dos agrotóxicos. Essa iniciativa além de beneficiar o solo e os alimentos, evitaria que os resíduos fossem despejados no aterro sanitário.

Ao desenvolver estas ações ambientais é importante que a instituição as evidencie para os diversos usuários das informações contábeis, através da elaboração da DVA, do Balanço Social e das notas explicativas.

Ressalta-se que esta proposta de plano resumido não possui a pretensão de solucionar todos os problemas apresentados durante a análise do índice de sustentabilidade ambiental da instituição, porém o mesmo possui o claro objetivo de auxiliar a instituição a melhorar seu índice de sustentabilidade ambiental. 


\section{CONSIDERAÇÕES FINAIS}

O objetivo geral desse trabalho foi analisar o nível de sustentabilidade ambiental da CeasaMinas. Nesse sentido, foi realizado o cálculo do índice de sustentabilidade desta instituição através da lista de verificação proposta pelo método SICOGEA, a qual foi aplicada em forma de questionário a três setores da CeasaMinas (contabilidade, comissão permanente de licitação e meio ambiente). O índice de sustentabilidade geral encontrado (40,5\%) mostrou que a instituição possui um nível de sustentabilidade classificado como Fraco, porém, próximo do índice considerado Regular (41\%), o qual demonstra que o desempenho socioambiental da entidade visa somente ao atendimento da legislação. O resultado obtido corrobora com a política adotada pela instituição apresentada durante a aplicação do questionário para a realização da pesquisa, a qual visa somente ao cumprimento do ordenamento legal das esferas municipal e estadual. Dessa forma, a discussão dos resultados desse estudo contribue para sensibilizar as partes envolvidas, no sentido de apresentar as informações ambientais como informações importantes para a tomada de decisões da instituição, dado que as atitudes ambientais impactam a sociedade como um todo.

Realizou-se o cálculo do índice de sustentabilidade dos grupos (Produção, Recursos Humanos, Marketing e Finanças e Contabilidade) e dos respectivos subgrupos e realizou-se a análise dos possíveis fatores que influenciaram cada índice.

Dos resultados obtidos, apenas os grupos Recursos Humanos e Marketing obtiveram índice considerado como Regular, sendo que o primeiro foi o grupo que apresentou o melhor percentual geral, destacando-se pelos projetos sociais desenvolvidos pela instituição como o Ceasa Cidadã e o Telecentro.

O índice de sustentabilidade do grupo Produção e Contabilidade e Finanças são considerados Fracos, sendo os principais subgrupos responsáveis por este resultado o Processo de Produção e a falta de auditoria e relatórios ambientais, respectivamente. Também pode ser destacado que o grupo Contabilidade e Finanças apresentou o menor índice entre os grupos analisados, chegando próximo ao nível considerado como Péssimo, decorrente da falta de divulgação de informações relacionadas a ações ambientais.

Foi elaborado o plano resumido de gestão ambiental onde procurou-se através da análise dos índices de sustentabilidade encontrados nos grupos e subgrupos, abordar os fatores mais deficitários e os que direta ou indiretamente causavam maior impacto ambiental. Neste aspecto foi priorizado o subgrupo que apresentou o menor índice de sustentabilidade (Contabilidade e Auditoria Ambiental) e as questões que possuíam alto nível de relevância e atingiram baixo 
atendimento da instituição. O plano foi estruturado de forma a demonstrar as ações e os objetivos propostos para melhorar o índice de sustentabilidade da CeasaMinas. Uma das sugestões foi a implantação do um SGA, que visa auxiliar a instituição no monitoramento e análise dos processos ambientais aos quais suas atividades estão envolvidas.

Embora os resultados encontrados não possam ser generalizados para as centrais de abastecimento, infere-se que a CeasaMinas necessita aperfeiçoar os processos que se referem a gestão ambiental, como por exemplo, o descarte correto dos produtos não aproveitados ou o incentivo de consumo consciente de papel, energia elétrica ou água.

Uma das lacunas deste trabalho centra-se na falta de discussão do plano resumido de gestão ambiental juntamente com os gestores da CeasaMinas para que o mesmo se apresentasse o mais próximo possível da realidade da instituição e que se pudesse orçar as ações previstas no plano para que houvesse a análise do custo benefício das ações propostas.

Destaca-se que o estudo foi desenvolvido com base em dados coletados por meio de entrevistas, sendo considerado dessa forma as respostas dos entrevistados como uma limitação do estudo. Considerou-se a integridade dos respondentes, bem como que as respostas oferecidas estão baseadas na veracidade da situação da instituição.

Ainda há muito que ser pesquisado nesta área de sustentabilidade das organizações, principalmente as organizações públicas, da administração direta e indireta, visto que a legislação estimula o aumento de esforços neste sentido e as organizações públicas devem ser vistas como exemplo para outras empresas.

\section{REFERENCIAS}

CEASAMINAS. Centrais de Abastecimento de Minas Gerais S.A, 2012. Disponível em: $<$ http://www.ceasaminas.com.br/>. Acesso em 1 abr. 2016.

CEASAMINAS. Relatório da Administração 2015. Belo Horizonte: 2016. Disponível em: $<$ http://pesquisa.in.gov.br/imprensa/jsp/visualiza/index.jsp?data=20/04/2016\&jornal=1\&pagi na $=5 \&$ totalArquivos=84>. Acesso em: 22 abr. 2016.

CEASAMINAS. Relatório de Gestão 2013. Belo Horizonte: 2014. Disponível em: $<$ http://www.agricultura.gov.br/arq_editor/Centrais\%20de $\% 20 \mathrm{Abastecimento} \% 20 \mathrm{de} \% 20 \mathrm{Min}$ as\%20Gerais\%20-\%20CEASAMINAS.pdf>. Acesso em: 22 abr. 2016.

CLARO, P. B. O.; CLARO, D. P.; AMÂNCIO, R. Entendendo o conceito de sustentabilidade nas organizações. Revista de Administração: da Universidade de São Paulo. São Paulo, v. 43, n. 4, p. 289-300, out/dez. 2008. Disponível em: $<$ http://200.232.30.99/busca/artigo.asp?num_artigo=1354>. Acesso em: 8 abr. 2016. 
COMISSÃO MUNDIAL SOBRE O MEIO AMBIENTE E DESENVOLVIMENTO. Nosso Futuro Comum. $2^{a}$ ed. Rio de Janeiro: Fundação Getúlio Vargas, 1991. Tradução de: Our comumon future, New York, Oxford University Press, 1987.

FILHO, J. C. G. S.; SICSÚ, A. B. Produção Mais Limpa: uma ferramenta da Gestão Ambiental aplicada as empresas nacionais. In: XXIII Encontro Nacional de Engenharia de Produção, 23, 2003, Ouro Preto. Anais... Ouro Preto: ENEGEP, 2003. Disponível em: $<$ http://www.abepro.org.br/biblioteca/enegep2003_tr1005_0001.pdf >. Acesso em: 3 abr. 2016.

KRAEMER, E. P.; BEHLING, G.; REBELO, H. M.; GOEDE, W. Gestão ambiental e sua contribuição para o desenvolvimento sustentável. In: Simpósio de excelência em gestão e tecnologia, 11., 2013, Resende. Anais... Resende: SEGeT, 2013. Disponível em <http://cetir.aedb.br/seget/artigos13/52118614.pdf>. Acesso em 4 abr. 2016.

LEITE, P. C.; PFTSCHER, E. D.; NUNES, J. P. O. Análise de Sustentabilidade socioambiental da CEASA/SC. Enfoque: Reflexão Contábil. Maringá, v. 30, n. 1, p. 49-62, jan./abr.2011. Disponível em: $<$ http://periodicos.uem.br/ojs/index.php/Enfoque/article/view/12152.pdf>. Acesso em 1 abr. 2016.

LINS, L. S.; SILVA, R. N. S. Responsabilidade Socioambiental ou Greenwash: uma avaliação com base nos relatórios de sustentabilidade ambiental. Sociedade, Contabilidade e Gestão. Rio de Janeiro, v. 4, n. 1, p. 91-105, jan/jun. 2009. Disponível em:

<http://www.atena.org.br/revista/ojs-2.2.3-06/index.php/ufrj/article/view/472>. Acesso em: 2 abr. 2016.

NUNES, J. P. O. Um aporte ao sistema contábil gerencial ambiental: elaboração e aplicação parcial do novo sistema em clínica hospitalar. 2010. 243 f. Dissertação (Mestrado em Contabilidade) - Programa de Pós-Graduação em Contabilidade, Universidade Federal de Santa Catarina, Florianópolis, 2010. Disponível em: <http://nemac.paginas.ufsc.br/files/2012/12/2010-Jo\%C3\%A3o-Paulo-Oliveira-Nunes.pdf>. Acesso em 1 abr. 2016.

PEREIRA, A. A. O tripé da sustentabilidade. Locus: Ambiente de Inovação brasileira. Brasília, v. 13, n. 50, p. 38-51, out/dez.2007. Disponível em: $<$ http://www.anprotec.org.br/ArquivosDin/gestao_pdf_55.pdf>. Acesso em 6 abr. 2016.

PFITSCHER, E. D.; NUNES, J. P. O.; BESEN, F.; TRÊS, D. L.; VAN BELLEN, H. M. Contribuições de Melhoria para o Sistema Contábil Gerencial Ambiental - SICOGEA.

Revista del Instituto Internacional de Costos. [S.I.], v. 5, n. 5, p. 119-140, jul./dez. 2009. Disponível em: <http://www.revistaiic.org/articulos/num5/articulo6_esp.pdf>. Acesso em: 3 abr. 2016.

RIBEIRO, M. S. Contabilidade Ambiental. 1ª ed. São Paulo: Saraiva, 2006.

RODRIGUES, R. D. Questionário. [mensagem pessoal]. Mensagem recebida por karinabatista.aquino@gmail.com em 25 mai. 2016. 
SACHS, I. Desarrollo sustentable, bio-industrialización descentralizada y nuevas configuraciones ruralurbanas. Los casos de India y Brasil. Pensamiento Iberoamericano, Madrid, v. 46, p. 235-256, 1990 apud SICHE, Raúl; et al. Índices versus indicadores: precisões conceituais na discussão da sustentabilidade de países. Ambiente \& Sustentabilidade. Campinas, v. X, n. 2, p. 137-148. Jul./dez. 2007. Disponível em: <http://www.scielo.br/pdf/asoc/v10n2/a09v10n2.pdf>. Acesso em: 7 abr. 2016.

SANTOS, T. L.; FADEL, A. M. R. A.; SOUZA, A. M. R. A. O grau de sustentabilidade ambiental á luz do modelo SICOGEA - um estudo de caso na empresa produtos alimentícios Pantera Ltda. Amazônia em foco. Castanhal, v. 2, n. 2, p. 136 - 156, jan./jun. 2013.

Disponível em: <http://revista.fcat.edu.br/index.php/path/article/view/44>. Acesso em: 1 abr. 2016.

SICHE, R.; AGOSTINHO, F.; ORTEGA, E.; ROMEIRO, A. Índices versus indicadores: precisões conceituais na discussão da sustentabilidade de países. Ambiente $\boldsymbol{\&}$

Sustentabilidade. Campinas, v. X, n. 2, p. 137-148. Jul./dez. 2007. Disponível em: <http://www.scielo.br/pdf/asoc/v10n2/a09v10n2.pdf>. Acesso em: 7 abr. 2016.

SILVA, G. R.; PFITSCHER, E. D. Gestão da sustentabilidade ambiental: estudo em uma instituição federal de ensino superior paranaense. Revista Enciclopédia Biosfera. Goiânia, v. 10, n. 18, p. 3912-3926. 2014. Disponível em:

$<$ http://www.conhecer.org.br/enciclop/2014a/MULTIDISCIPLINAR/gestao.pdf>. Acesso em: 2 abr. 2016.

TINOCO, J. E. P.; KRAEMER, M. E. P. Contabilidade e Gestão Ambiental. $3^{\text {a }}$ ed. São Paulo: Atlas, 2011.

TINOCO, J. E. P.; ROBLES, L. T. A contabilidade da gestão ambiental e sua dimensão para a transparência empresarial: estudo de caso de quatro empresas brasileiras com atuação global.

Revista de Administração Pública. Rio de Janeiro, v. 40, n. 6, p. 1077-1096, nov./dez. 2006.

UHLMANN, V. O. Contribuições ao desenvolvimento do Sistema Contábil Gerencial Ambiental - Geração 2: proposição da terceira geração do método. 2011. 130 f. Dissertação (Mestrado em Contabilidade) - Programa de Pós-Graduação em Contabilidade do Centro Socioeconômico, Universidade Federal de Santa Catarina, Florianópolis, 2011. Disponível em: <https://repositorio.ufsc.br/handle/123456789/94709>. Acesso em: 5 abr. 2016.

VELOSO, N. Questionário. [mensagem pessoal]. Mensagem recebida por karinabatista.aquino@gmail.com em 17 mai. 2016.

VELLANI, C. L.; RIBEIRO, M. S. Sustentabilidade e Contabilidade. Revista Contemporânea de Contabilidade. Florianópolis, v. 1, n. 11, p. 187-206, jan./jun. 2009. Disponível em: <https://periodicos.ufsc.br/index.php/contabilidade/article/view/21758069.2009v6n11p187>. Acesso em: 2 abr. 2016. 